\title{
The natural history of peanut allergy
}

\author{
Helen S. Skolnick, MD, a Mary Kay Conover-Walker, MSN, RN, CRNP,a Celide Barnes \\ Koerner, MS, RD, a Hugh A. Sampson, MD, besley Burks, MD, ${ }^{c}$ and Robert A. \\ Wood, MDa Baltimore, Md, New York, NY, and Little Rock, Ark
}

\begin{abstract}
Background: It has traditionally been assumed that peanut allergy is rarely outgrown.

Objective: The goal of this study was to determine the number of children with peanut allergy who become tolerant of peanut. Methods: Patients aged 4 to 20 years with a diagnosis of peanut allergy were evaluated by questionnaire, skin testing, and a quantitative antibody fluorescent-enzyme immunoassay. Patients who had been reaction free in the past year and had a peanut IgE (PN-IgE) level less than 20 kilounits of antibody per liter $\left(\mathrm{kU}_{\mathrm{A}} / \mathrm{L}\right)$ were offered an open or double-blind, placebo-controlled peanut challenge.
\end{abstract}

Results: A total of $\mathbf{2 2 3}$ patients were evaluated, and of those, 85 (PN-IgE $<$ 0.35-20.4 kU $_{\mathrm{A}} / \mathrm{L}$ [median $1.42 \mathrm{kU}_{\mathrm{A}} / \mathrm{L}$ ]) participated in an oral peanut challenge. Forty-eight $(21.5 \%)$ patients had negative challenge results and were believed to have outgrown their peanut allergy (aged 4-17.5 years [median 6 years]; PN-IgE $<0.35-20.4 \mathrm{kU}_{\mathrm{A}} / \mathrm{L}$ [median $0.69 \mathrm{kU}_{\mathrm{A}} / \mathrm{L}$ ]). Thirty-seven failed the challenge (aged 4-13 years [median 6.5 years]; RAST < 0.35-18.2 $\mathrm{kU}_{\mathrm{A}} / \mathrm{L}$ [median $2.06 \mathrm{kU}_{\mathrm{A}} / \mathrm{L}$ ]). Fortyone patients with $\mathrm{PN}$-IgE levels less than $20 \mathrm{kU}_{\mathrm{A}} / \mathrm{L}$ declined to undergo challenge, and 97 were not eligible for challenge because their PN-IgE levels were greater than $20 \mathrm{kU}_{\mathrm{A}} / \mathrm{L}$ or they had had a recent reaction. Sixty-seven percent of patients with PN-IgE levels less than $2 \mathrm{kU}_{\mathrm{A}} / \mathrm{L}$ and $61 \%$ with levels less than $5 \mathrm{kU}_{\mathrm{A}} / \mathrm{L}$ had negative challenge results. Of those who underwent challenge, PN-IgE levels for those who passed versus those who failed were different at the time of challenge $(P=.009)$, but not at the time of diagnosis $(P=.25)$.

Conclusion: This study demonstrates that peanut allergy is outgrown in about $21.5 \%$ of patients. Patients with low PNIgE levels should be offered a peanut challenge in a medical setting to demonstrate whether they can now tolerate peanuts. (J Allergy Clin Immunol 2001;107:367-74.)

Key words: Peanut allergy; double-blind, placebo-controlled food challenge; RAST; food hypersensitivity

From athe Department of Pediatrics, Johns Hopkins University, Baltimore; bthe Department of Pediatrics, Mount Sinai Hospital, New York; and cthe Department of Pediatrics, University of Arkansas for Medical Sciences, Little Rock.

Supported by training grant T32 AI 07007 from the NIH, the Eudowood Foundation for the Consumptives of Maryland, Johns Hopkins University School of Medicine General Clinical Research Center, NIH grant AI01666-02, NIH/NCRR grant M01 RR00052, NIH grant AI43668, and the Food Allergy Initiative.

Received for publication July 31, 2000; revised September 26, 2000; accepted for publication September 29, 2000.

Reprint requests: Helen S. Skolnick, MD, CMSC 1102, Johns Hopkins Hospital, 600 N Wolfe St, Baltimore, MD 21287-3923.

Copyright $\odot 2001$ by Mosby, Inc.

$0091-6749 / 2001 \$ 35.00+0 \quad \mathbf{1 / 8 7 / 1 1 2 1 2 9}$

doi:10.1067/mai.2001.112129

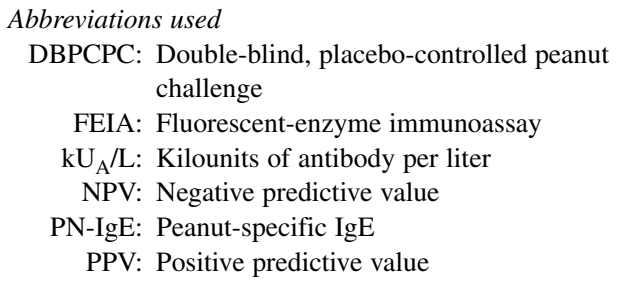

The diagnosis of peanut allergy carries with it great medical and emotional significance. ${ }^{1,2}$ Patients and their families are advised to be extremely cautious with all foods consumed and that peanut allergy reactions can be severe and even fatal. With less red meat being consumed and health foods, vegetarianism, and prepared foods becoming more prevalent, peanut is more commonly used as a source of protein. This leads to both an increased risk of exposure as well as possible nutritional consequences.

Food allergy is very common in the first 3 years of life, with up to $6 \%$ to $8 \%$ of children being affected. ${ }^{3}$ Longitudinal studies have shown that most food allergies that begin early in life, such as to egg and cow's milk, typically resolve over time. Up to $80 \%$ of infants with egg allergy are able to consume egg by 5 years of age, and up to $85 \%$ of children with cow's milk allergy are tolerant of milk by 3 years of age. ${ }^{4-6}$ Although it was previously thought that virtually all peanut sensitivity was lifelong, anecdotal observations have suggested that some children do in fact outgrow their allergy. In addition, a recent report from the United Kingdom on the natural history of peanut allergy in a small population found that $9.6 \%$ of peanut allergic children appeared to have lost their sensitivity over time. ${ }^{7}$

In this study we sought to determine the frequency with which peanut allergy is outgrown and any characteristics that might predict this tendency. We identified patients with a history of peanut allergy and investigated their initial and subsequent reactions to peanut, as well as their history of other atopic diseases, through chart review and a detailed questionnaire. Subsequently, skin testing to peanut and quantification of peanut-specific $\operatorname{IgE}(\mathrm{PN}-\mathrm{IgE})$ levels were performed. Those who met preset criteria were invited to undergo an oral peanut challenge. In addition, we attempted to determine the efficacy of the CAP System quantitative antibody fluorescent-enzyme immunoassay (FEIA; Pharmacia, Uppsala, Sweden) in predicting challenge outcome in this population of patients. 


\section{METHODS \\ Study population}

From January 1998 to March 2000, patients 4 years and older with a diagnosis of peanut allergy were identified by review of charts from the Johns Hopkins Pediatric Allergy Clinic, the Arkansas Children's Hospital Pediatric Allergy Clinic, and a private allergy office. Patients were determined to have peanut allergy if they had a history of an acute reaction to peanut ingestion and positive results to a skin test, RAST, or challenge, or in some cases, positive results to RAST or a skin test for peanut with no history of ever ingesting peanut. Patients whose PN-IgE levels were higher than 20 kilounits of antibody per liter $\left(\mathrm{kU}_{\mathrm{A}} / \mathrm{L}\right)$ or who had had a reaction in the prior year were classified as having ongoing peanut allergy and were not studied further. All other patients were enrolled in the following study protocol, which was approved by the investigational review boards of the Johns Hopkins University School of Medicine and the University of Arkansas for Medical Sciences College of Medicine.

Patients accompanied by their parents were seen in the Clinical Research Center at Johns Hopkins Hospital or the Arkansas Children's Hospital. A questionnaire was administered to establish a detailed clinical history, including the age of onset of the peanut allergy, the characteristics of all prior peanut reactions, any other food allergies and their resolution or lack of resolution, and any history of other atopic diseases. Antihistamines (short acting, 72 hours; long acting, 7 days) were restricted before the first visit and the food challenges. Unless there was objection by the family or a history of severe anaphylaxis to peanuts, a puncture skin test to peanut was performed. Patients with a PN-IgE level of less than $20 \mathrm{kU}_{\mathrm{A}} / \mathrm{L}$ who had only cutaneous symptoms after peanut ingestion were asked to participate in an oral peanut challenge. In patients with a history of a severe reaction, a $\mathrm{PN}-\mathrm{IgE}$ level of $10 \mathrm{kU}_{\mathrm{A}} / \mathrm{L}$ was used as the cutoff for challenge eligibility. Both double-blind, placebo-controlled and open food challenges were used during the course of the study.

\section{Diagnosis of other food allergies}

Other food allergies, such as to milk or egg, were diagnosed if patients had both a history of an acute reaction to that food and a positive skin test or RAST result, or if they had a food-specific IgE level above that determined to be greater than $95 \%$ predictive of a positive challenge result to that food. ${ }^{8}$ Tree nut allergy was diagnosed if patients had a history of an acute reaction and/or a positive skin test or RAST result to 1 or more tree nuts. Wheat, soy, or other legume allergies or other less common food allergies (eg, mustard) were diagnosed only if patients had a positive challenge result or both a clinical reaction and a positive skin test or RAST result.

\section{Laboratory studies}

Puncture skin tests. Puncture skin tests were performed through a standard technique with a Wyeth needle (Becton Dickinson Co, Baltimore, Md). A glycerinated peanut extract (1:20; Greer Laboratories, Lenoir, NC) and positive (histamine) and negative (saline solution) controls were applied. The mean diameters of both the wheal and erythema were measured after 15 minutes. To be considered positive, the wheal had to be at least $3 \mathrm{~mm}$ greater than that of the negative control. A scoring system was used that compared each patient's peanut result to his or her histamine result as follows: 0 , no wheal present; $1+$, wheal less than half of the histamine diameter; $2+$, wheal greater than or equal to half of the histamine diameter; $3+$, wheal equal to histamine diameter; $4+$, wheal greater than histamine diameter but less than 2 times the histamine diameter; and $5+$, wheal greater than or equal to 2 times the histamine diameter.

CAP-RAST System FEIA. Venous serum samples were analyzed for circulating IgE to peanut with the CAP-System FEIA. After the samples were obtained, the serum was separated and stored at $-20^{\circ} \mathrm{C}$ until analysis. The assay had a lower limit of detection of $0.35 \mathrm{kU}_{\mathrm{A}} / \mathrm{L}$ and an upper limit of $100 \mathrm{kU}_{\mathrm{A}} / \mathrm{L}$, with higher values simply reported as greater than $100 \mathrm{kU}_{\mathrm{A}} / \mathrm{L}$.

Peanut challenges For the double-blind, placebo-controlled peanut challenges (DBPCPCs), $4 \mathrm{~g}$ of peanut protein was disguised in $84 \mathrm{~g}$ of either milk-free chocolate or ground chicken/turkey with barbecue sauce. As a texture and flavor control, oatmeal was used in the placebo. A physician or nurse who was blinded to the testing material administered the challenge in 6 divided doses given every 15 minutes. The first dose contained $0.2 \mathrm{~g}$ of peanut protein $(5 \%$ of the challenge), and subsequent doses were increased to $0.4 \mathrm{~g}(10 \%)$, $0.6 \mathrm{~g}(15 \%), 0.8 \mathrm{~g}(20 \%), 1.0 \mathrm{~g}(25 \%)$, and $1.0 \mathrm{~g}(25 \%)$. The active and placebo challenges were performed on 2 separate days. After each challenge the patient was observed for 4 hours. Reactions were recorded as to type, severity, time of onset, and duration. At any sign of objective or subjective symptoms deemed clinically significant, the challenge was terminated, and appropriate medical treatment was administered. The nutrition department of the Pediatric Clinical Research Unit prepared and randomized each challenge. All negative challenge results were confirmed by an open challenge, which consisted of ingestion of $8 \mathrm{~g}$ of peanut in the form of peanut butter or peanuts in candy. For the open challenges, the equivalent dose of peanut protein as peanut butter was mixed in juice, and the challenge was performed with the same increasing dose schedule described previously.

\section{Statistical analysis}

For analysis, patients were separated into the following 4 categories: patients who passed the peanut challenge, patients who failed the challenge, patients who refused to be challenged although they did meet the eligibility requirements, and those who were unable to be challenged because they had PN-IgE levels greater than $20 \mathrm{kU}_{\mathrm{A}} / \mathrm{L}$ or a recent history of reaction. In addition to comparing patients who passed the challenge with those who failed, patients who passed the challenge were compared with patients who had ongoing peanut allergy, defined as those who could not be challenged plus those who failed the challenge.

PN-IgE concentrations, as determined by the CAP-System FEIA, were compared by use of the Mann-Whitney $U$ test. The frequencies of asthma, allergic rhinitis, atopic dermatitis, and other food allergies in these groups were compared by use of the $\chi^{2}$ test. The performance characteristics of the CAP-System FEIA, including sensitivity, specificity, positive predictive value (PPV), and negative predictive value (NPV), were calculated with PN-IgE cutoff values of 0.35 $\mathrm{kU}_{\mathrm{A}} / \mathrm{L}$ (the lower limit of detection), $2 \mathrm{kU}_{\mathrm{A}} / \mathrm{L}$, and $5 \mathrm{kU}_{\mathrm{A}} / \mathrm{L}$.

\section{RESULTS}

A total of 223 patients in whom peanut allergy had been diagnosed, with an age range at the time of evaluation of 4 to 20 years (median 6.5 years), participated in the study (Table I); 212 patients were evaluated at Johns Hopkins and 11 at Arkansas Children's Hospital. There were 140 male (63\%) and 83 female (37\%) patients, and peanut allergy had been diagnosed in each between the ages of 2 months and 15 years (median 1.5 years). The initial diagnosis was made on the basis of a history of an acute reaction to peanut in 167 patients, 164 of whom also had a positive skin test and/or RAST result. Of the remaining 66 patients, 11 had diagnoses based on positive skin test or RAST results and a marked improvement in atopic dermatitis with a peanut-restricted diet; 54 who were never known to have ingested peanuts were diag- 
TABLE I. Patient characteristics

\begin{tabular}{|c|c|c|c|c|c|}
\hline & $\begin{array}{l}\text { Passed challenge } \\
\quad(n=48)\end{array}$ & $\begin{array}{l}\text { Failed challenge } \\
\qquad(n=37)\end{array}$ & $\begin{array}{l}\text { Unable to be challenged } \\
\qquad(n=97)\end{array}$ & $\begin{array}{l}\text { Refused challenge } \\
\qquad(n=41)\end{array}$ & $\begin{array}{c}\text { Total } \\
(n=223)\end{array}$ \\
\hline Male (\%) & $28(58)$ & $26(70)$ & $61(63)$ & $25(61)$ & $140(63)$ \\
\hline Female $(\%)$ & $20(42)$ & $11(30)$ & $36(37)$ & $16(39)$ & $83(37)$ \\
\hline \multicolumn{6}{|l|}{ Current age (y) } \\
\hline Range & $4-17.5$ & $4-13$ & $4-20$ & $4-16.5$ & $4-20$ \\
\hline Median & 6 & 6.5 & 7 & 7 & 6.5 \\
\hline \multicolumn{6}{|l|}{ Current PN-IgE $\left(\mathrm{kU}_{\mathrm{A}} / \mathrm{L}\right)$} \\
\hline Range & $<0.35-20.4$ & $<0.35-18.2$ & $16.8->100$ & $<0.35-16.9$ & $<0.35->100$ \\
\hline Median & 0.69 & 2.06 & $>100$ & 4.98 & 10.7 \\
\hline $\begin{array}{l}\text { No. diagnosed by } \\
\text { RAST/skin test/bot }\end{array}$ & $11 / 34 / 2$ & $11 / 18 / 6$ & $31 / 49 / 17$ & $13 / 16 / 12$ & $66 / 117 / 37$ \\
\hline $\begin{array}{l}\text { No. diagnosed by } \\
\text { history/challenge }\end{array}$ & $1 / 0$ & $0 / 2$ & $0 / 0$ & $0 / 0$ & $1 / 2$ \\
\hline \multicolumn{6}{|l|}{ Age at diagnosis } \\
\hline Range & $8 \mathrm{mo}$ to $12 \mathrm{y}$ & $6 \mathrm{mo}$ to $4 \mathrm{y}$ & $2 \mathrm{mo}$ to $10 \mathrm{y}$ & $8 \mathrm{mo}$ to $15 \mathrm{y}$ & $2 \mathrm{mo}$ to $15 \mathrm{y}$ \\
\hline Median (y) & 1.5 & 1.5 & 1.5 & 2 & 1.5 \\
\hline \multicolumn{6}{|c|}{$\mathrm{PN}-\mathrm{IgE}$ at diagnosis $\left(\mathrm{kU}_{\mathrm{A}} / \mathrm{L}\right)$} \\
\hline Range & $<0.35-52.9$ & $1.8-24.4$ & $4.5->100$ & $0.64->100$ & $<0.35->100$ \\
\hline Median & 2.2 & 2.91 & $>100$ & 6.27 & 19.8 \\
\hline
\end{tabular}

nosed by only a positive skin test or RAST result ( 8 of whom subsequently did have acute reactions), and 1 had a positive skin test result and a PN-IgE level greater than $20 \mathrm{kU}_{\mathrm{A}} / \mathrm{L}$ but had a history of accidental peanut ingestion without reaction. The racial distribution was as follows: 182 white (81\%), 29 African American (13\%), 10 Asian American (5\%), and 2 Hispanic (1\%). The initial diagnosis was made by skin test in 117 patients $(52.5 \%)$, by RAST in 66 patients $(29.6 \%)$, by both skin test and RAST in 37 patients $(16.6 \%)$, by history in 1 patient $(0.4 \%)$, and by food challenge in 2 patients $(0.9 \%)$.

On the basis of the history and PN-IgE levels, 126 patients were eligible for a peanut challenge. Forty-one patients (16 female and 25 male), ranging in age from 4 to 16.5 years (median 7 years), declined further participation in the study and did not undergo challenge. The PN-IgE levels of these patients ranged from $<0.35$ to $16.9 \mathrm{kU}_{\mathrm{A}} / \mathrm{L}$ (median $4.98 \mathrm{kU}_{\mathrm{A}} / \mathrm{L}$ ). The remaining 85 patients (31 female and 54 male), aged from 4 to 17.5 years (median 6 years), participated in either a DBPCPC $(33 \%)$ or open peanut challenge $(67 \%)$. The PN-IgE levels of the patients challenged ranged from $<0.35$ to 20.4 $\mathrm{kU}_{\mathrm{A}} / \mathrm{L}$ (median $1.42 \mathrm{kU}_{\mathrm{A}} / \mathrm{L}$ ). The age at diagnosis for the group challenged ranged from 6 months to 12 years (median 1.5 years), and the initial PN-IgE levels (drawn at diagnosis or at $<2$ years of age), which were available for 30 patients, ranged from $<0.35$ to $52.9 \mathrm{kU}_{\mathrm{A}} / \mathrm{L}$ (median $2.9 \mathrm{kU}_{\mathrm{A}} / \mathrm{L}$ ).

The peanut challenge results were negative in 48 patients $(21.5 \%$ of the 223 patients), who ranged in age from 4 to 17.5 years (median 6 years). As seen in Table I and Fig 1, PN-IgE levels for those who had negative challenge results ranged from $<0.35$ to $20.4 \mathrm{kU}_{\mathrm{A}} / \mathrm{L}$ (median $0.69 \mathrm{kU}_{\mathrm{A}} / \mathrm{L}$ ), compared with $<0.35$ to 18.2 $\mathrm{kU}_{\mathrm{A}} / \mathrm{L}$ (median $2.06 \mathrm{kU}_{\mathrm{A}} / \mathrm{L}$ ) in the group who reacted $(P$ $=.009)$. Seventy-three percent of children with a negative
RAST results $\left(<0.35 \mathrm{kU}_{\mathrm{A}} / \mathrm{L}\right), 67 \%$ with $\mathrm{PN}-\mathrm{IgE}$ levels less than $2.0 \mathrm{kU}_{\mathrm{A}} / \mathrm{L}$, and $61 \%$ with PN-IgE levels less than $5.0 \mathrm{kU}_{\mathrm{A}} / \mathrm{L}$ had negative challenge results. The age of diagnosis for those who passed the challenge ( 8 months to 12 years, median 1.5 years) was not significantly different from that of those who failed (6 months to 4 years, median 1.5 years; $P=.083$ ). Initial PN-IgE levels, available in 16 of the 48 patients who passed the challenge, were not different from those of patients who failed, available in 14 of 37 patients $\left(2.2 \mathrm{vs} 2.91 \mathrm{kU}_{\mathrm{A}} / \mathrm{L}\right.$, $P=.25$ ) (Fig 2). Only 2 of the 54 patients with initial PNIgE levels greater than $10 \mathrm{kU}_{\mathrm{A}} / \mathrm{L}$ outgrew their peanut allergy (levels of 10.4 and $52.9 \mathrm{kU}_{\mathrm{A}} / \mathrm{L}$, respectively).

In patients who were unable to be challenged, PN-IgE levels ranged from 18.2 to $100 \mathrm{kU}_{\mathrm{A}} / \mathrm{L}$ (median $>100$ $\mathrm{kU}_{\mathrm{A}} / \mathrm{L}$ ) (Fig 1). Initial PN-IgE levels, available in 52 of these 97 patients, ranged from 4.5 to $>100 \mathrm{kU}_{\mathrm{A}} / \mathrm{L}$ (median $\left.>100 \mathrm{kU}_{\mathrm{A}} / \mathrm{L}\right)($ Fig 2). Both the current and initial PNIgE levels of patients who were unable to be challenged, as well as those with ongoing peanut allergy (patients who failed challenge plus those unable to be challenged), were significantly higher than the levels of those who passed the challenge (all $P$ values $<.0001$ ).

Sixty-six patients whose allergies had been diagnosed by skin test or RAST alone initially did not have a clinical history of either an acute reaction or exposure to peanuts. Broken down by group, of the 13 patients whose allergies were initially diagnosed by skin or RAST testing alone and who passed the peanut challenge, 11 had no history of peanut ingestion, 1 had a subsequent positive challenge result before passing this challenge, and 1 had accidental peanut ingestion without reaction (RAST $20.4 \mathrm{kU}_{\mathrm{A}} / \mathrm{L}$ ). Of the 8 patients who failed the challenge, 7 had no history of peanut ingestion, and 1 had a subsequent reaction to peanut before the challenge. In the 27 patients who were unable to be challenged, 18 had no 


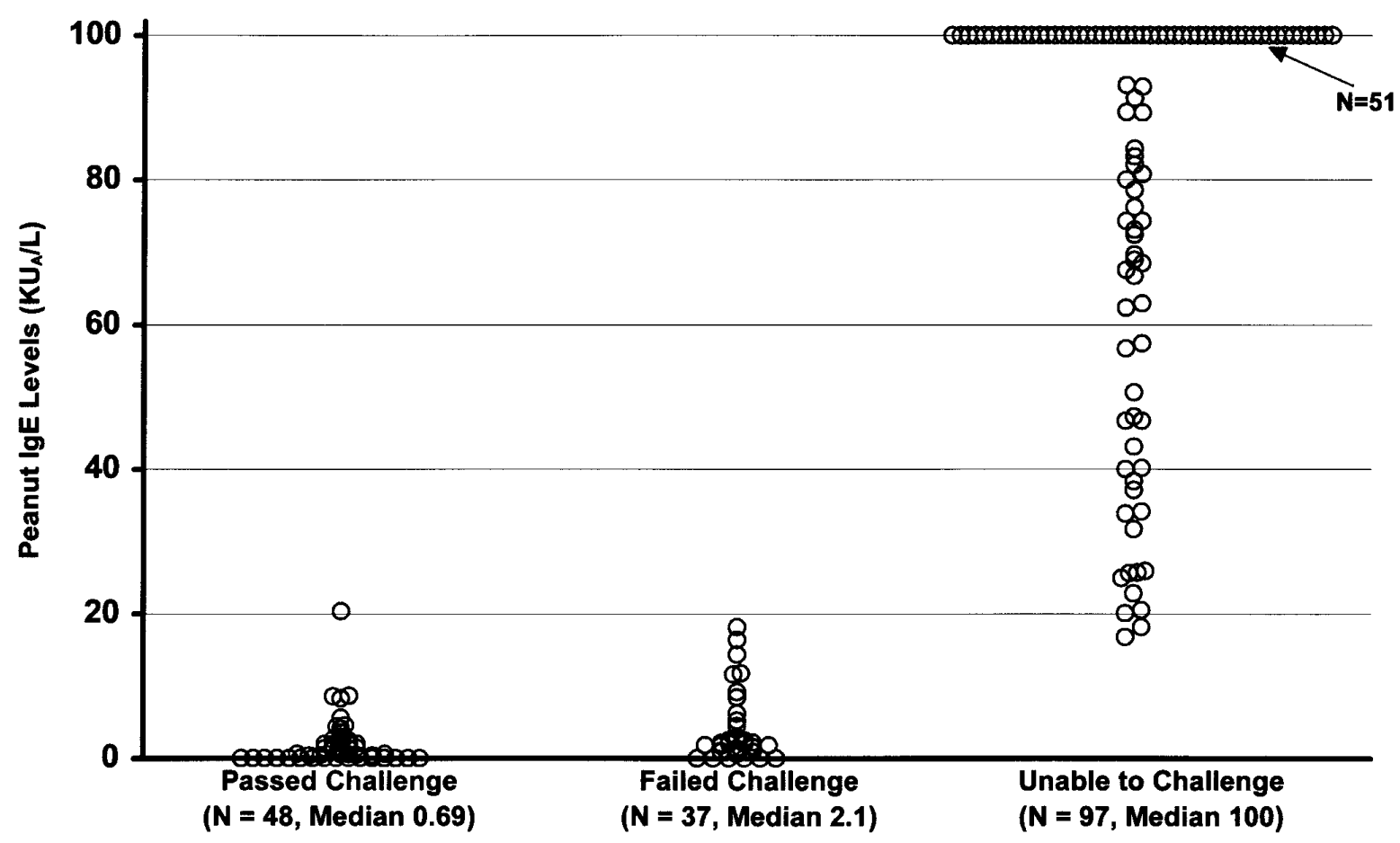

FIG 1. Current $\mathrm{PN}-\mathrm{IgE}$ levels in patients who passed the challenge, who failed the challenge, or who were unable to be challenged.

TABLE II. Comparison of skin test results for patients undergoing peanut challenge

\begin{tabular}{ccc}
\hline Skin test result & $\begin{array}{c}\text { Passed challenge } \\
(\mathbf{n}=\mathbf{2 3})\end{array}$ & $\begin{array}{c}\text { Failed challenge } \\
(\mathbf{n}=\mathbf{2 1})\end{array}$ \\
\hline 0 & 8 & 2 \\
$1+$ & 2 & 0 \\
$2+$ & 0 & 1 \\
$3+$ & 9 & 5 \\
$4+$ & 4 & 6 \\
$5+$ & 0 & 7 \\
\hline
\end{tabular}

history of peanut ingestion, 4 had a subsequent reaction to peanut ingestion, and 6 had marked improvement in their atopic dermatitis with a peanut-restricted diet. In the 18 patients who refused the challenge, 10 had no history of peanut ingestion, 5 had marked improvement in atopic dermatitis with a peanut-restricted diet, and 3 had subsequent reactions to peanut ingestion.

Skin tests were performed in 23 of 48 patients who passed the challenge and 21 of 37 patients who failed (Table II). Skin tests were positive in 15 of $23(63 \%)$ patients who passed the challenge, with 13 having a skin test grade of $3+$ or above. Nineteen of $21(90 \%)$ patients who failed the challenge had a positive skin test grade of $2+$ or above. Of the 10 patients who had negative skin test results, 2 had positive challenge results.

Initial reactions to peanut exposure are described in Table III. Forty-four percent of patients had involvement of the skin only. Of these, $19 \%$ had a rash on the face only,
$6 \%$ had an acute eczematous rash, and $19 \%$ had hives and/or angioedema. A few patients had initial reactions involving only the respiratory or gastrointestinal systems ( $2 \%$ and $4 \%$, respectively), whereas $9 \%$ had involvement of 2 systems, and $11 \%$ had involvement of 3 systems. Patients who had negative peanut challenge results were significantly more likely to have had an initial reaction with involvement of only the skin than those with ongoing peanut allergy $(P=.03)$. Although patients with ongoing peanut allergy were more likely to have had an initial reaction involving all 3 systems $(P=.03), 1$ child with involvement of all 3 systems did outgrow his allergy.

Eighty-eight percent of patients had 1 or more atopic disorder other than food allergy (Table IV). Fifty-nine percent had asthma, $60 \%$ had allergic rhinitis, $58 \%$ had atopic dermatitis, $76 \%$ had a history of food allergy to a food other than peanut, and $5 \%$ had no atopic disease other than peanut allergy. Similar rates of asthma and allergic rhinitis were observed in the patients who passed and failed the challenge, as well as in those who were unable to be challenged. However, patients who outgrew their allergies had a lower rate of atopic dermatitis than those who failed the challenge and those with ongoing peanut allergy $(P=.04$ and .06 , respectively).

Examination of associated food allergies revealed that $76 \%$ of the 223 patients had a history of another food allergy, with similar rates observed in each group of patients (Table V). The most common associated food allergies were egg (55\%), milk (41\%), and tree nuts (40\%). In addition, $15 \%$ of the patients had allergy to soy and $4 \%$ to another legume. Comparison of patients who passed the 


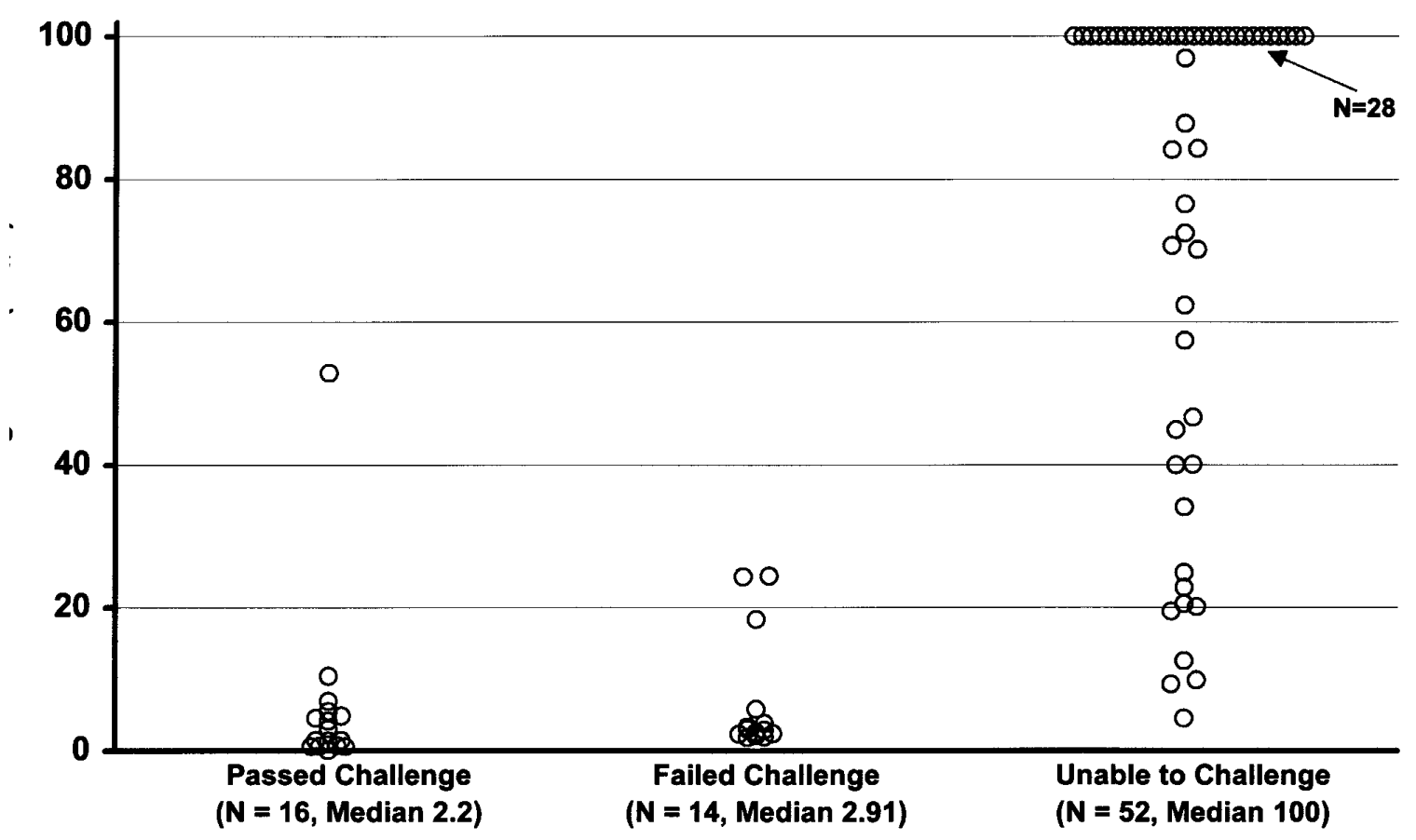

FIG 2. Initial PN-IgE levels in patients who passed the challenge, who failed the challenge, or who were unable to be challenged.

challenge with those who had ongoing peanut allergy revealed that the patients with tree nut allergy tended to be less likely to outgrow their peanut allergy $(P=.058)$.

Of the patients who had negative peanut challenge results, $42 \%$ had outgrown at least 1 other food allergy, compared with $51 \%$ of the patients who failed the challenge and $29 \%$ of those who were unable to be challenged $(P=.04$, passed challenge vs ongoing peanut allergy). In addition, although $50 \%$ of patients who outgrew peanut allergy had a history of egg allergy, only $19 \%$ currently carry this diagnosis, compared with $40 \%$ of those with ongoing peanut allergy $(P<.005)$.

Seventy percent of the patients have ongoing allergies to foods other than peanut (Table V). Thirty-nine percent have egg allergy, 30\% have milk allergy, and 39\% have tree nut allergy. The incidences of soy and other legume allergy decreased to $6 \%$ and $3 \%$, respectively. The current prevalence of other food allergies was slightly different between the groups, with $58 \%$ of those who passed the challenge remaining allergic to other foods, compared with $54 \%$ and $77 \%$ of those who failed the challenge and who were unable to be challenged $(P=.035$, passed challenge vs ongoing peanut allergy).

The ability of the CAP-System FEIA to predict challenge outcome was analyzed with 3 different levels of PN-IgE (Table VI). A PN-IgE of more than $0.35 \mathrm{kU}_{\mathrm{A}} / \mathrm{L}$ had a sensitivity of $83.8 \%$, a specificity of $33.3 \%$, a PPV of $49.2 \%$, and an NPV of $72.7 \%$. If a cutoff value of 2 $\mathrm{kU}_{\mathrm{A}} / \mathrm{L}$ was used, the sensitivity was $54.1 \%$, the specificity was $72.7 \%$, the PPV was $60.6 \%$, and the NPV was $67.3 \%$. When $5 \mathrm{kU}_{\mathrm{A}} / \mathrm{L}$ was used as the cutoff, the sensi- tivity was $24.3 \%$, the specificity was $89.6 \%$, and the PPV and NPV were $64.3 \%$ and $60.6 \%$, respectively.

\section{DISCUSSION}

It is clear from this study that a subset of children do indeed outgrow their peanut allergy. Although this is contrary to the traditional view of peanut allergy, ${ }^{2}$ it is most likely not a new phenomenon. In the past, when there was generally less awareness regarding peanut allergy among both primary caretakers and parents, children who may have had a reaction to peanut were typically advised to avoid the food for 1 to 2 years and then reintroduce it at home. Those who had another reaction very likely did have life-long peanut allergy, and those who did not react never came to medical attention. Now, however, it is more common for children to be referred for evaluation after their initial reaction, so that we are now seeing more children with the short-lived variety of peanut allergy.

Although it is certain that peanut allergy can be outgrown, our result of $21.5 \%$ could be either an overestimate or underestimate for several reasons. First, although 126 patients qualified for a challenge, only 85 elected to participate in the challenge. Although the patients who declined challenge tended to have higher PN-IgE levels (median $4.98 \mathrm{kU}_{\mathrm{A}} / \mathrm{L}$ ) than those who were challenged, many had very low PN-IgE levels and even negative skin test results. Because these patients were used in the denominator to calculate the final result, the estimate of $21.5 \%$ is almost certainly an underestimate. Second, although most of the children who were not challenged 
TABLE III. Characteristics of initial peanut reactions

\begin{tabular}{|c|c|c|c|c|c|}
\hline & $\begin{array}{c}\text { Passed challenge } \\
(\%)\end{array}$ & $\begin{array}{l}\text { Failed challenge } \\
\qquad(\%)\end{array}$ & $\begin{array}{c}\text { Unable to be challenged } \\
(\%)\end{array}$ & $\begin{array}{c}\text { Refused challenge } \\
(\%)\end{array}$ & $\begin{array}{l}\text { Total } \\
(\%)\end{array}$ \\
\hline Rash or hives on face only & $13(27)$ & $9(24)$ & $18(18)$ & $3(7)$ & $43(19)$ \\
\hline Eczema & $2(4)$ & $1(3)$ & $7(7)$ & $3(7)$ & $13(6)$ \\
\hline Hives/angioedema & $14(29)$ & $10(27)$ & $12(12)$ & $6(15)$ & $42(19)$ \\
\hline Respiratory only & $1(2)$ & $1(3)$ & $3(3)$ & $0(0)$ & $5(2)$ \\
\hline GI only & $1(2)$ & $2(5)$ & $4(4)$ & $1(2)$ & $8(4)$ \\
\hline Skin and respiratory & $2(4)$ & $1(3)$ & $6(6)$ & $3(7)$ & $12(6)$ \\
\hline Skin and GI & $0(0)$ & $2(5)$ & $4(4)$ & $1(2)$ & $7(3)$ \\
\hline GI and respiratory & $1(2)$ & $1(3)$ & $1(1)$ & $0(0)$ & $3(1)$ \\
\hline All 3 systems & $1(2)$ & $2(5)$ & $15(17)$ & $6(15)$ & $24(11)$ \\
\hline Positive SPT or RAST only & $13(27)$ & $8(22)$ & $27(28)$ & $18(44)$ & $66(30)$ \\
\hline
\end{tabular}

GI, Gastrointestinal; SPT, skin prick test.

TABLE IV. Associated atopic disorders

\begin{tabular}{|c|c|c|c|c|c|}
\hline & $\begin{array}{c}\text { Passed challenge } \\
(\%)\end{array}$ & $\begin{array}{l}\text { Failed challenge } \\
(\%)\end{array}$ & $\begin{array}{l}\text { Unable to be challenged } \\
(\%)\end{array}$ & $\begin{array}{c}\text { Refused challenge } \\
(\%)\end{array}$ & $\begin{array}{l}\text { Total } \\
(\%)\end{array}$ \\
\hline Asthma & $26(54)$ & $17(46)$ & $60(62)$ & $28(68)$ & $131(59)$ \\
\hline Allergic rhinitis & $27(56)$ & $19(51)$ & $58(60)$ & $30(73)$ & $134(60)$ \\
\hline Atopic dermatitis & $22(46)$ & $25(68)$ & $57(59)$ & $26(63)$ & $130(58)$ \\
\hline Current other food allergies & $28(58)$ & $20(54)$ & 75 (77) & $36(88)$ & $159(70)$ \\
\hline History of other food allergies & $32(67)$ & $25(68)$ & $77(79)$ & $36(88)$ & $170(76)$ \\
\hline Outgrown food allergies & $20(42)$ & $19(51)$ & $28(29)$ & $13(32)$ & $80(36)$ \\
\hline $\begin{array}{l}\text { No atopic disorder except food } \\
\text { allergy (other than peanut) }\end{array}$ & $5(10)$ & $5(14)$ & $5(5)$ & $1(2)$ & $16(7)$ \\
\hline No other atopic disorder & $4(8)$ & $2(5)$ & $3(3)$ & $1(2)$ & $10(5)$ \\
\hline
\end{tabular}

TABLE V. Other food allergy

\begin{tabular}{lccccc}
\hline & \multicolumn{5}{c}{ History/challenge } \\
\cline { 2 - 6 } Food & $\begin{array}{c}\text { Passed challenge } \\
(\mathbf{n}=\mathbf{4 8})\end{array}$ & $\begin{array}{c}\text { Failed challenge } \\
(\mathbf{n}=\mathbf{3 7})\end{array}$ & $\begin{array}{c}\text { Unable to be challenged } \\
\mathbf{( n = 9 7 )}\end{array}$ & $\begin{array}{c}\text { Refused challenge } \\
(\mathbf{n = 4 1 )}\end{array}$ & $\begin{array}{c}\text { Total } \\
(\mathbf{n = 2 2 3})\end{array}$ \\
\hline Milk & $15 / 10$ & $17 / 8$ & $42 / 34$ & $17 / 15$ & $91(41 \%) / 67(30 \%)$ \\
Egg & $24 / 9$ & $14 / 5$ & $57 / 49$ & $28 / 24$ & $123(55 \%) / 87(39 \%)$ \\
Soy & $6 / 1 *$ & $5 / 1$ & $16 / 9$ & $7 / 3$ & $34(15 \%) / 14(6 \%)$ \\
Other legumes & $2 / 0$ & $2 / 1$ & $5 / 5$ & $0 / 0$ & $9(4 \%) / 6(3 \%)$ \\
Tree nuts & $14 / 13$ & $13 / 13$ & $47 / 47$ & $15 / 15$ & $89(40 \%) / 88(39 \%)$ \\
Wheat & $5 / 1$ & $4 / 0$ & $16 / 11$ & $7 / 5$ & $32(14 \%) / 17(8 \%)$ \\
Shellfish & $7 / 5$ & $5 / 4$ & $20 / 20$ & $13 / 11$ & $45(20 \%) / 40(18 \%)$ \\
Other & $13 / 9$ & $14 / 7$ & $42 / 34$ & $26 / 20$ & $95(43 \%) / 70(31 \%)$ \\
Total & $32(67 \%) / 28(58 \%)$ & $25(68 \%) / 20(54 \%)$ & $77(79 \%) / 75(77 \%)$ & $36(88 \%) / 36(88 \%)$ & $170(76 \%) / 159(71 \%)$ \\
\hline
\end{tabular}

*This patient was offered a soy challenge but declined.

TABLE VI. Performance characteristics of the CAP-RAST at different cutoff values to predict a positive challenge result

\begin{tabular}{lcccc}
\hline RAST cutoff value & Sensitivity (\%) & Specificity (\%) & PPV (\%) & NPV (\%) \\
\hline$>0.35 \mathrm{kU}_{\mathrm{A}} / \mathrm{L}$ & 83.8 & 33.3 & 49.2 & 72.7 \\
$\geq 2 \mathrm{kU}_{\mathrm{A}} / \mathrm{L}$ & 54.1 & 72.7 & 60.6 & 67.3 \\
$\geq 5 \mathrm{kU}_{\mathrm{A}} / \mathrm{L}$ & 24.3 & 89.6 & 64.3 & 60.6 \\
\hline
\end{tabular}

because of high PN-IgE levels were likely to be peanut allergic, at least a few could have passed a challenge. Third, the patients included in this study may not be typical of all patients with peanut allergy in that they were being seen in tertiary-care facilities, which was further suggested by the very high percentage of patients with multiple food allergies. Finally, open peanut challenges were conducted in two thirds of the patients, and some of the positive challenge results could have been due to physiologic stress rather than true allergic reactivity.

Conversely, the result could be an overestimate because of the inclusion of patients whose allergies were 
diagnosed by skin test or RAST only and who had never been exposed to peanuts or had a clinical reaction. The specificity and PPV of skin and RAST testing are quite low, and in one report, only $33 \%$ of children whose allergies were diagnosed by skin testing alone were found to be truly peanut allergic. ${ }^{9}$ It is unlikely that the inclusion of these children had a major effect on our results, however, because there was a similar percentage in each group of patients. However, if we assume that only a third of the 13 children in this group who passed their challenge had true peanut allergy, and that all of these children in the other groups had true peanut allergy, the estimate would fall to as low as $17.5 \%$.

PN-IgE levels were significantly lower in the group of patients who passed the challenge (median 0.69) than in those who failed (median 2.06) and those who could not be challenged (median $>100$ ). These levels are very different from those reported by Sampson and $\mathrm{Ho}^{8}$ in their study examining the relationship between food-specific IgE levels and challenge outcome. In that study, patients with positive peanut challenge results had a median PNIgE of $47.2 \mathrm{kU}_{\mathrm{A}} / \mathrm{L}$, compared with $2.0 \mathrm{kU}_{\mathrm{A}} / \mathrm{L}$ for patients who had negative challenge results. These differences are not surprising, however, because we did not offer challenges to those with PN-IgE levels greater than $20 \mathrm{kU}_{\mathrm{A}} / \mathrm{L}$, who were believed to almost certainly have peanut allergy based on that prior study.

Overall, we found that PN-IgE levels were the best guide to determine which patients should be considered for a formal challenge. However, it should also be noted there were 6 patients with negative RAST results and 2 with both negative RAST and skin test results who had positive challenge results (1 open and 1 DBPCPC). The reactions during challenge in this group varied from limited urticaria to multisystem involvement, which emphasizes the limitations of these test methods and the importance or performing all challenges in a controlled setting.

Although many children did not have a RAST performed at the time of diagnosis, the data on initial PNIgE levels that we do have suggest that these may also provide valuable predictive information. Although the initial PN-IgE levels were similar for those children who passed and failed the challenge, when all children with ongoing peanut allergy were included in the analysis, the results were markedly different. A low initial PN-IgE level therefore improves the odds of eventually outgrowing peanut allergy, whereas a higher initial level was associated with much poorer odds. In fact, only 2 of 54 (4\%) patients with an initial PN-IgE level greater than 10 $\mathrm{kU}_{\mathrm{A}} / \mathrm{L}$ outgrew their peanut allergy.

Initial reactions to peanut exposure also had some predictive value with regard to future peanut allergy status. Patients who outgrew their allergies were significantly more likely to have initial reactions involving only the skin than those with ongoing peanut allergy. In addition, patients with initial reactions involving 3 systems were significantly more likely to have ongoing peanut allergy, although 1 patient with such a reaction did outgrow his peanut allergy. Twenty percent of the study population had an initial reaction localized to the face only, many of which involved only a few hives around the mouth. Although we had anticipated that these children might be the most likely to lose their reactivity, this did not appear to be the case.

Forty-one percent of the patients had a history of milk allergy, and 55\% had a history of egg allergy. An unexpected finding was that the patients in this study were far less likely to have outgrown their milk and egg allergies by the time they were 4 years or older (26\% and $29 \%$, respectively), as compared with previous reports on the natural history of milk and egg allergy. ${ }^{4-7}$ Future followup will be needed to determine whether they remain allergic to these foods or whether patients who have peanut allergy tend to outgrow their associated food allergies at a slower rate. As with other studies of peanut allergy, many patients had an associated tree nut allergy. ${ }^{10,11}$ In addition, we found a somewhat higher rate of allergy to soy and other legumes $(15 \%)$ than was previously reported in children with peanut allergy. ${ }^{12}$

Bock and Atkins ${ }^{2}$ reported an earlier study on the natural history of peanut allergy in 36 patients ranging in age from 2 to 14 years in which no patients outgrew their allergies. More recently, the idea of life-long peanut allergy was challenged by Hourihane et $\mathrm{al},{ }^{7}$ who examined patients with a clinical history of peanut allergy, beginning at a median age of 11 months, in a case control study. They found that $9.6 \%$ of patients who had restricted peanuts from their diet were no longer allergic to peanuts. In our study we found that a higher percentage of patients outgrew their allergy to peanuts, most likely because the patients who were challenged in our study were selected by history and PN-IgE level rather than by history or parent request and skin test result, as was done by Hourihane et al. As in our study, they found that patients who outgrew their peanut allergy had a lower rate of eczema and were more likely to have outgrown other food allergies. However, contrary to our data, their findings showed that patients who outgrew peanut allergy also had lower rates of asthma and allergic rhinitis.

We conclude that approximately $20 \%$ of children with peanut allergy do outgrow their allergy. Although patients with an initial PN-IgE level greater $10 \mathrm{kU} / \mathrm{L}$ are unlikely to outgrow their allergy, we would still recommend rechecking PN-IgE levels for all patients on a yearly basis at least through the age of 4 years because we did have 2 patients with high initial PN-IgE levels who outgrew their allergy. Although some may question whether it is ethical to challenge patients to a highly allergenic food, the benefits provided to those who are shown to no longer be allergic clearly outweigh the risks of a carefully performed challenge. Although the ideal cutoff for challenge eligibility has not been established, we have shown that $61 \%$ of patients with a PN-IgE level less than $5 \mathrm{kU}_{\mathrm{A}} / \mathrm{L}$ and $67 \%$ with a PN-IgE level less than $2 \mathrm{kU}_{\mathrm{A}} / \mathrm{L}$ had negative challenge results. We therefore recommend that patients with peanut allergy who are older than 4 years and who have a PN-IgE level less than $5 \mathrm{kU}_{\mathrm{A}} / \mathrm{L}$ be considered for a formal challenge in a hospital setting. 


\section{REFERENCES}

1. Hourihane JO. Peanut allergy — current status and future challenges. Clin Exp Allergy 1997;27:1240-5.

2. Bock SA, Atkins FM. The natural history of peanut allergy. J Allergy Clin Immunol 1989;83:900-4

3. Bock SA. Prospective appraisal of complaints of adverse reactions to foods in children during the first 3 years of life. Pediatrics 1987;79:683-8.

4. Sampson HA, McCaskill CC. Food hypersensitivity in atopic dermatitis: evaluation of 113 patients. J Pediatr 1985;107:669-75.

5. Dannaeus A, Inganaes M. A follow-up study of children with food allergy. Clinical course to serum IgE and IgG antibody levels to milk, egg and fish. Clin Allergy 1981;11:533-9.

6. Host A, Halken S. A prospective study of cow milk allergy in Danish infants during the first 3 years of life. Allergy 1990;45:587-96.

7. Hourihane JO, Roberts SA, Warner JO. Resolution of peanut allergy: case control study. BMJ 1998;316:1271-5.
8. Sampson HA, Ho DG. Relationship between food specific IgE concentrations and the risk of positive food challenges in children and adolescents. J Allergy Clin Immunol 1997;100:444-51.

9. Hayami D, Kagan R. The positive predictive value of skin prick tests to peanuts in children who have never previously eaten peanuts [abstract]. $\mathrm{J}$ Allergy Clin Immunol 2000;105:S189.

10. Ewan PW. Clinical study of peanut and nut allergy in 62 consecutive patients: new features and association. BMJ 1996;312:1074-8.

11. Sicherer SH, Burks AW, Sampson HA. Clinical features of acute allergic reactions to peanut and tree nuts in children [online]. Pediatrics 1998;102:e6.

12. Bernhisel-Broadbent J, Sampson HA. Cross-allergenicity in the legume botanical family in children with food hypersensitivity. J Allergy Clin Immunol 1898;83:435-40.

\section{Bound volumes available to subscribers}

Bound volumes of The Journal of Allergy and Clinical Immunology are available to subscribers (only) for the 2001 issues from the Publisher, at a cost of $\$ 107.00$ for domestic, and $\$ 128.00$ for international subscribers for Vol. 107 (January-June) and Vol. 108 (July-December). Shipping charges are included. Each bound volume contains a subject and author index, and all advertising is removed. Copies are shipped within 30 days after publication of the last issue in the volume. The binding is durable buckram with the journal name, volume number, and year stamped in gold on the spine. Payment must accompany all orders. Contact Mosby, Subscription Customer Service, 6277 Sea Harbor Dr, Orlando, FL 32887; phone (800) 654-2452 or (407) 3454000 .

Subscriptions must be in force to qualify. Bound volumes are not available in place of a regular journal subscription. 